\title{
Acute respiratory distress syndrome: does histology matter?
}

\author{
José A. Lorente ${ }^{1,2,3}$, Aida Ballén-Barragán ${ }^{1}$, Raquel Herrero ${ }^{1,2}$ and Andrés Esteban 1,2,3* \\ See related research by Kao et al., http://www.ccforum.com/content/19/1/228
}

\begin{abstract}
Kao et al. have reported in Critical Care the histological findings of 101 patients with acute respiratory distress syndrome (ARDS) undergoing open lung biopsy. Diffuse alveolar damage (DAD), the histological hallmark of ARDS, was present in only $56.4 \%$ of cases. The presence of DAD was associated with higher mortality. Evidence from this and other studies indicates that the clinical criteria for the diagnosis of ARDS identify DAD in only about half of the cases. On the contrary, there is evidence that the clinical course and outcome of ARDS differs in patients with DAD and in patients without DAD. The discovery of biomarkers for the physiological (increased alveolocapillary permeability) or histological (DAD) hallmarks of ARDS is thus of paramount importance.
\end{abstract}

Kao et al. [1] have made an important contribution to the knowledge of the histological changes associated with acute respiratory distress syndrome (ARDS) and the potential role of open lung biopsy (OLB) in the diagnosis and management of ARDS. The authors studied the histological findings in OLB from 101 patients with a diagnosis of ARDS over 15 years. Indications for OLB included a suspicion of noninfectious cause that could benefit from corticosteroid treatment. Notwithstanding the obvious selection bias, histological information from OLB or autopsy tissue samples is of cardinal importance for a better understanding of the pathogenesis and management of ARDS. Kao et al.'s [1] main findings are that diffuse alveolar damage (DAD) was present in only

\footnotetext{
* Correspondence: aesteban@ucigetafe.com

${ }^{1}$ Hospital Universitario de Getafe, Carretera de Toledo km 12500, 28905

Madrid, Spain

${ }^{2}$ CIBER de Enfermedades Respiratorias, Instituto de Salud Carlos III, Calle Sinesio Delgado, 4, 28029 Madrid, Spain

Full list of author information is available at the end of the article
}

$56.4 \%$ of patients with ARDS, and that the presence of DAD was associated with a worse outcome in patients with ARDS. The results of OLB, in accordance with other studies [2-5], changed management in a substantial proportion of patients.

ARDS is a syndrome of acute respiratory failure due to pulmonary inflammation developing after a known risk factor, leading to increased endothelial and epithelial permeability, pulmonary edema, hypoxemia, loss of aerated tissue, decreased lung compliance, and bilateral opacities in the chest X-ray image. The histological correlate of ARDS is DAD, characterized by lung edema, inflammation, hemorrhage, hyaline membranes, and alveolar epithelial cell injury [6-8].

The agreement between the clinical diagnosis of ARDS according to commonly accepted criteria [7, 8] and the presence of DAD at histological examination is poor, ranging from 13 to $58 \%$ in studies using OLB $[2-5,9,10]$ and from 45 to $88 \%$ in autopsy studies [11-16]. In two autopsy studies using the Berlin definition of ARDS [8], DAD was present in only $45 \%$ of patients diagnosed with ARDS [11, 12].

Conditions identified in patients without DAD include, among others, organizing pneumonia, eosinophilic pneumonia, pulmonary embolism, drug-induced pneumonitis, alveolar hemorrhage, lymphangitis, malignancy, or vasculitis. Of note, in one study [12] $14 \%$ of patients with ARDS did not have pathological changes, probably representing cases with diffuse atelectasis that appear clinically as ARDS but resolve as the lungs are inflated at high pressure prior to fixation.

Many of the conditions identified at the histological examination do not share the same pathogenesis, treatment, and biomarkers as DAD. The failure of previous studies into the treatment of ARDS has thus been attributed in part to a lack of a reliable definition of ARDS designating a homogeneous phenotype.

The importance of identifying a homogeneous phenotype in ARDS is highlighted by the finding in the study 
by Kao et al. [1] of different mortality rates in patients with DAD and in patients without DAD (71.9 \% versus $41.5 \%$ ). In a recent study, Guerin et al. [9] reported in 83 patients with ARDS undergoing OLB a higher airway plateau pressure, worse oxygenation, and (not reaching statistical significance) higher mortality in patients with DAD versus patients without DAD. These findings $[1,9]$ together suggest that the histological finding of DAD defines a specific population of patients within the syndrome of ARDS.

The heterogeneity of conditions designated with the same clinical diagnostic criteria as well as data suggesting that the clinical course differs in patients with DAD and in patients without DAD thus underline the importance of identifying patients with specific clinicopathological phenotypes within those diagnosed with ARDS.

Another challenge for our understanding of ARDS is the identification of the mechanisms explaining why some patients with a clinical risk factor go on to develop ARDS whereas others do not. Hopefully, the recognition of these patients at risk should be accomplished early in their course, before the requirement of ventilatory support. Biomarkers should thus be determined in the blood rather than in bronchoalveloar lavage fluid.

In conclusion, after almost five decades of research [6], ARDS continues to pose challenges for physicians and scientists. The discovery of markers for the physiological (e.g., alveolocapillary hyperpermeability) or histological (hyaline membrane) hallmarks of ARDS is of great import for the identification of a specific phenotype within ARDS.

\section{Abbreviations}

ARDS: Acute respiratory distress syndrome; DAD: Diffuse alveolar damage; OLB: Open lung biopsy.

\section{Competing interests}

The authors declare that they have no competing interests.

\section{Acknowledgements}

This manuscript has been funded by FIS PI 12/02898 and FIS PI 12/02451 (Instituto de Salud Carlos III, Madrid, Spain).

\section{Author details}

${ }^{1}$ Hospital Universitario de Getafe, Carretera de Toledo km 12500, 28905 Madrid, Spain. ${ }^{2}$ CIBER de Enfermedades Respiratorias, Instituto de Salud Carlos III, Calle Sinesio Delgado, 4, 28029 Madrid, Spain. ${ }^{3}$ Universidad Europea de Madrid, Calle Tajo, s/n, 28670 Villaviciosa de Odón, Madrid, Spain.

Published online: 15 September 2015

\section{References}

1. Kao KC, Hu HC, Chang CH, Hung CY, Chiu LC, Li SH, et al. Diffuse alveolar damage associated mortality in selected acute respiratory distress syndrome patients with open lung biopsy. Crit Care. 2015;19:228.

2. Papazian L, Thomas P, Bregeon F, Garbe L, Zandotti C, Saux P, et al. Open-lung biopsy in patients with acute respiratory distress syndrome. Anesthesiology. 1998:88:935-44.

3. Patel SR, Karmpaliotis D, Ayas NT, Mark EJ, Wain J, Thompson BT, et al. The role of open-lung biopsy in ARDS. Chest. 2004;125:197-202.
4. Kao KC, Tsai YH, Wu YK, Chen NH, Hsieh MJ, Huang SF, et al. Open lung biopsy in early-stage acute respiratory distress syndrome. Crit Care. 2006;10:R106.

5. Papazian L, Doddoli C, Chetaille B, Gernez Y, Thirion X, Roch A, et al. A contributive result of open-lung biopsy improves survival in acute respiratory distress syndrome patients. Crit Care Med. 2007;35:755-62.

6. Ashbaugh DG, Bigelow DB, Petty TL, Levine BE. Acute respiratory distress in adults. Lancet. 1967;2:319-23.

7. Bernard GR, Artigas A, Brigham KL, Carlet J, Falke K, Hudson L, et al. The American-European Consensus Conference on ARDS: definitions, mechanisms, relevant outcomes, and clinical trial coordination. Am J Respir Crit Care Med. 1994;149:818-24.

8. Definition Task Force ARDS, Ranieri VM, Rubenfeld GD, Thompson BT, Ferguson ND, Caldwell E, et al. Acute respiratory distress syndrome: the Berlin Definition. JAMA. 2012;307:2526-33.

9. Guerin C, Bayle F, Leray V, Debord S, Stoian A, Yonis H, et al. Open lung biopsy in nonresolving ARDS frequently identifies diffuse alveolar damage regardless of the severity stage and may have implications for patient management. Intensive Care Med. 2015;41:222-30.

10. Lim SY, Suh GY, Choi JC, Koh WJ, Lim SY, Han J, et al. Usefulness of open lung biopsy in mechanically ventilated patients with undiagnosed diffuse pulmonary infiltrates: influence of comorbidities and organ dysfunction. Crit Care. 2007;11:R935

11. Esteban A, Fernández-Segoviano P, Frutos-Vivar F, Aramburu JA, Nájera L, Ferguson ND, et al. Comparison of clinical criteria for the acute respiratory distress syndrome with autopsy findings. Ann Intern Med. 2004;141:440-5.

12. Thille AW, Esteban A, Fernández-Segoviano P, Rodriguez JM, Aramburu JA, Peñuelas $\mathrm{O}$, et al. Comparison of the Berlin definition for the acute respiratory distress syndrome with autopsy. Am J Respir Crit Care Med. 2013;187:761-7.

13. de Hemptinne $Q$, Remmelink M, Brimioulle $S$, Salmon I, Vincent JL. ARDS: a clinicopathological confrontation. Chest. 2009;135:944-9.

14. Pinheiro BV, Muraoka FS, Assis RV, Lamin R, Pinto SP, Ribeiro Jr PJ, et al. Accuracy of clinical diagnosis of acute respiratory distress syndrome in comparison with autopsy findings. J Bras Pneumol. 2007;33:423-8.

15. Sarmiento X, Almirall J, Guardiola JJ, Mesalles E, Labarta L, Mate JL, et al. Estudio sobre la correlación clínico-patológica en el síndrome de distrés respiratorio agudo secondario (Clinico-pathological correlation in secondary adult respiratory distress syndrome). Med Intensiva. 2011;35:22-7.

16. Sarmiento X, Guardiola JJ, Almirall J, Mesalles E, Mate JL, Soler M, et al. Discrepancy between clinical criteria for diagnosing acute respiratory distress syndrome secondary to community acquired pneumonia with autopsy findings of diffuse alveolar damage. Respir Med. 2011;105:1170-5. 